\title{
Biomass Production and Withaferin A Synthesis by Withania somnifera Grown in Aeroponics and Hydroponics
}

\author{
Philipp von Bieberstein', Ya-ming Xu, A.A. Leslie Gunatilaka, \\ and Raphael Gruener \\ Southwest Center for Natural Products Research and Commercialization, \\ School of Natural Resources \& the Environment, College of Agriculture and \\ Life Sciences, The University of Arizona, 250 E. Valencia Road, Tucson, AZ \\ 85750-6800
}

Additional index words. optimization of plant secondary metabolites synthesis, plant pharmaceuticals, soilless plant culture, natural products

\begin{abstract}
The medicinal herb Withania somnifera (L.) Dunal (Solanaceae) was grown in two soilless systems to determine optimal conditions for production of biomass and withaferin A, the major secondary metabolite responsible for its claimed medicinal properties. Withaferin A content was analyzed using high-performance liquid chromatography (HPLC). The results show that there was no statistically significant difference $(P>0.05$; $t$ test) in biomass production between the plants grown aeroponically and hydroponically. Aeroponically grown plants produced an average of $49.8 \mathrm{~g}$ dried aerial plant material (DW) (sD 20.7) per plant, whereas hydroponically grown plants produced an average of 57.6 g DW (SD 16.0). In contrast, withaferin A content was statistically higher in plants grown hydroponically. These plants contained an average of $7.8 \mathrm{mg} \cdot \mathrm{g}^{-1} \mathrm{DW}$ (SD 0.3 ), whereas the aeroponically grown plants contained an average of $5.9 \mathrm{mg} \cdot \mathrm{g}^{-1} \mathrm{DW}$ (SD 0.6 ). These results demonstrate that hydroponic techniques are optimal in reproducibly and efficiently generating withaferin $\mathrm{A}$. These findings may be of importance to the natural products industry in seeking to maximize production of biologically active compounds from medicinal plants.
\end{abstract}

Intensified interest in plant secondary metabolites for anticancer and other disease treatments has led to recent exploration of medicinal plant growth conditions to optimize biomass production and metabolite synthesis (Cragg et al., 2009; Nagella and Murthy, 2011). Our study compares these variables for Withania somnifera when grown under soilless hydroponic and aeroponic conditions. W. somnifera (L.) Dunal (Solanaceae) has been used for over 3000 years in the Ayurvedic medical tradition of India (Dalavayi et al., 2006). Preparations of dried root powder called "ashwagandha" have been administered as a general tonic to increase energy, improve overall health and longevity, and to prevent diseases (Xu et al., 2009). Currently, considerable attention is focused on the anticancer properties of one of the secondary metabolites, withaferin A (WA), of this medicinal plant (Mishra et al., 2000). It is therefore important to determine how to increase plant biomass and WA production by comparing outcomes from traditional, in-soil growing conditions with soilless hydroponic and aeroponic conditions in controlled greenhouse environments. Growing plants in controlled environments (greenhouses),

Received for publication 25 Aug. 2014. Accepted for publication 6 Oct. 2014.

${ }^{1}$ To whom reprint requests should be addressed; e-mail pbieberstein@email.arizona.edu. and afford a more rigorously controlled, year-round growing environment.

\section{Materials and Methods}

Seeds of Withania somnifera were obtained from the Natural Product Center (NPC; University of Arizona) stock collection ( 6 months old, stored at $4{ }^{\circ} \mathrm{C}$ ). They were germinated in 1-inch Grodan rockwool cubes in a germination chamber kept at $28^{\circ} \mathrm{C}$ with $16 \mathrm{~h}$ of fluorescent lighting. After $\approx 5$ weeks (late summer), seedlings with an aerial length of $\approx 5 \mathrm{~cm}$ were transferred to a float system [deep water culture containing $50 \%$ modified Hoagland Nutrient Medium (Hoagland and Arnon, 1950); see composition in Table 1] in the greenhouse $\left[25^{\circ} \mathrm{C}, 45 \%\right.$ relative humidity $(\mathrm{RH})$ and a light shadecloth to protect from direct sunlight]. The nutrient medium (NM) was stone-aerated using an air pressure pump (EcoPlus Commercial Air 5) for 1 min every $5 \mathrm{~min}$ to promote aerial plant and root growth. When the plants reached an aerial height of 10 to $15 \mathrm{~cm}(\approx 6$ weeks) (in early fall), they were transferred to an aeroponics box measured $1.0 \mathrm{~m} \times 1.0 \mathrm{~m} \times 1.5 \mathrm{~m}$ (width $\times$ length $\times$ height) or to a hydroponic system (nutrient film technique with drip irrigation using a $5^{\prime \prime} \times 5^{\prime \prime} \times 10^{\prime \prime}$ polyvinyl chloride pipe). Both systems were located in the same greenhouse. There were seven plants in the aeroponics box and seven plants in the hydroponics system. In both environments, the interplant distance was the same at $20 \mathrm{~cm}$. In the aeroponics system, plants were arranged on the periphery of a square platform, whereas in the hydroponic system, the plants were arranged linearly. Therefore, in both systems, the plant density was similar. Plants in the aeroponics system were irrigated with NM for $1 \mathrm{~min}$ every $4 \mathrm{~min}$ and in the hydroponics system for $1 \mathrm{~min}$ every $10 \mathrm{~min}$. The hydroponic system contained a small volume of nutrient film in the pipe so that the roots were exposed to nutrients even when irrigation was off. For both systems, the NM was sourced from the same reservoir containing the NM with a $\mathrm{pH}$ of 5.9 and electroconductivity (EC) of $1.85 \mathrm{dS} \cdot \mathrm{m}^{-1}$.

Plant growth was assessed by measuring the height of all plants and calculating the weekly averages for both systems. In addition, the surface area of one average-sized leaf of six randomly chosen plants per system was measured every week and weekly averages were calculated. This was done by tracing the leaf (while remaining on the plant) on a plain paper and cutting it out on paper. This paper was weighed and the surface area determined by using a predetermined surface area of paper-to-weight ratio. To measure plant biomass production, all plants were harvested at the flowering stage ( 8 weeks after transfer to the two growth conditions), and both wet and dry weights were recorded for aerial and root segments. The aerial parts were weighed individually per plant and the roots were measured as a total for each system. The plants were dried in a dark and warm drying room $\left(39^{\circ} \mathrm{C}, 17 \% \mathrm{RH}\right)$ for $14 \mathrm{~d}$. 
Table 1. Composition of nutrient medium (NM). ${ }^{\mathrm{z}}$

\begin{tabular}{lll}
\hline & $\mathrm{mm}$ & $\mathrm{g} \cdot \mathrm{L}^{-1}$ \\
\hline $\mathrm{Ca}\left(\mathrm{NO}_{3}\right)_{2} 4 \mathrm{H}_{2} \mathrm{O}$ & 1.95 & 0.46 \\
$\mathrm{CaCl}_{2} 6 \mathrm{H}_{2} \mathrm{O}$ & 1.01 & 0.22 \\
$\mathrm{Fe}-\mathrm{EDDHA}^{2} \%$ & 0.07 & 0.024 \\
$\mathrm{MgSO}_{4} 7 \mathrm{H}_{2} \mathrm{O}$ & 1.95 & 0.48 \\
$\mathrm{KH}_{2} \mathrm{PO}_{4}$ & 1.2 & 0.16 \\
$\mathrm{~K}_{2} \mathrm{SO}_{4}$ & 0.89 & 0.15 \\
$\mathrm{MnSO}_{4} \mathrm{H}_{2} \mathrm{O} 20 \%$ & 0.003 & 0.003 \\
$\mathrm{ZnSO}_{4} 7 \mathrm{H}_{2} \mathrm{O} 20 \%$ & 0.002 & 0.003 \\
$\mathrm{H}_{3} \mathrm{BO}_{3}$ & 0.03 & 0.002 \\
$\mathrm{CuSO}_{4} 20 \%$ & 0.003 & 0.002 \\
$\mathrm{Na}_{2} \mathrm{MoO}_{4} 2 \mathrm{H}_{2} 0$ & 0.004 & 0.001 \\
\hline
\end{tabular}

zThis Hoagland-modified NM was used to irrigate plants in both hydroponic and aeroponic systems.

All data were statistically analyzed to determine the mean, SD, and statistical parameters ( $t$ test) using Microsoft Excel ${ }^{\mathrm{TM}}$ (Microsoft Inc., Redmond, WA).

We are aware that there is a division of opinion in the plant science research community concerning the validity of using statistical analysis in studies such as ours, where true sample replication was not undertaken and where, instead, the process of pseudoreplication of samples was used (South and Somers, 2009; Wilson, 2007). As far as costs, timing, and inherent additional concerns resulting from replication in the greenhouse, we chose not to repeat the experiments described here but to rely on the strength of differences in the various parameters which we measured (biomass, WA production), especially as evidenced from statistical analysis.

Air-dried foliage was combined for each growing condition and pulverized (Wiley Mill, Model No. 2). Three representative samples of $1.0 \mathrm{~g}$ each were extracted with $10.0 \mathrm{~mL} 60 \%$ aqueous methanol and subjected to $2 \mathrm{~h}$ of ultrasonic vibration and stored at room temperature for 1 week. The extracts were then filtered and washed twice with $2 \mathrm{~mL}$ of $60 \%$ aqueous methanol $(\mathrm{MeOH})$. The solvent was evaporated to dryness using a Buchi rotavapor (water bath at $40{ }^{\circ} \mathrm{C}$ ). The remaining residues were re-dissolved in 2.0 $\mathrm{mL} \mathrm{MeOH}$ and filtered through cotton. Each solution was diluted 1:10 with $\mathrm{MeOH}$ and subjected to HPLC on a Kromasil $\mathrm{C}_{18} \mathrm{RP}$ column $\left(250 \times 4.6 \mathrm{~mm}, 5 \mu \mathrm{m}, 0.7 \mathrm{~mL} \cdot \mathrm{min}^{-1}\right.$ flow rate) with gradient elution using $40 \%$ to $100 \%$ aqueous $\mathrm{MeOH}$ and ultraviolet-Vis detection at $229 \mathrm{~nm}$. An external standard curve method was used to calculate the concentrations of WA in all samples.

\section{Results}

Seed germination rate was $34 \%$ (data not shown). Plant growth analysis showed trends but no statistically significant differences between the aeroponically and hydroponically grown plants (Figs. 1 and 2), although during the first 3 weeks, aeroponically grown plants developed faster. A power outage occurred 30 $\mathrm{d}$ after the plants had been transplanted to their systems (during Week 5) resulting in a temperature rise to $50{ }^{\circ} \mathrm{C}$ and disabling the pumps supplying NM to both systems for $\approx 4 \mathrm{~h}$. As

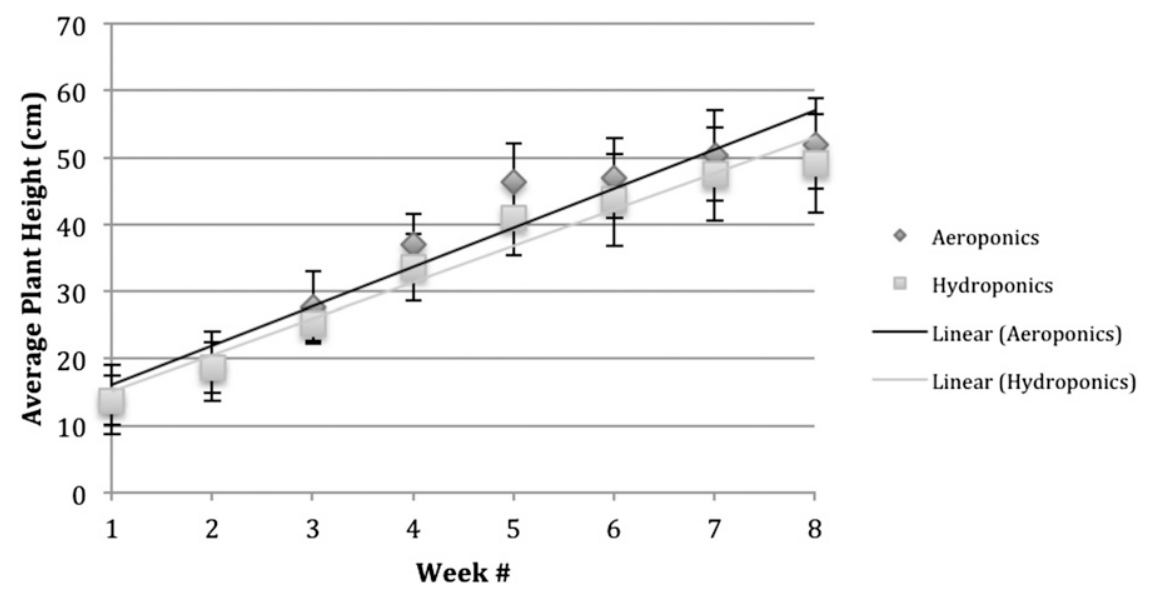

Fig. 1. Aerial plant size grown aeroponically and hydroponically. Vertical bars represent $95 \%$ confidence interval. Diamonds and squares represent weekly averages $(\mathrm{n}=7)$ and lines represent linear best fit.

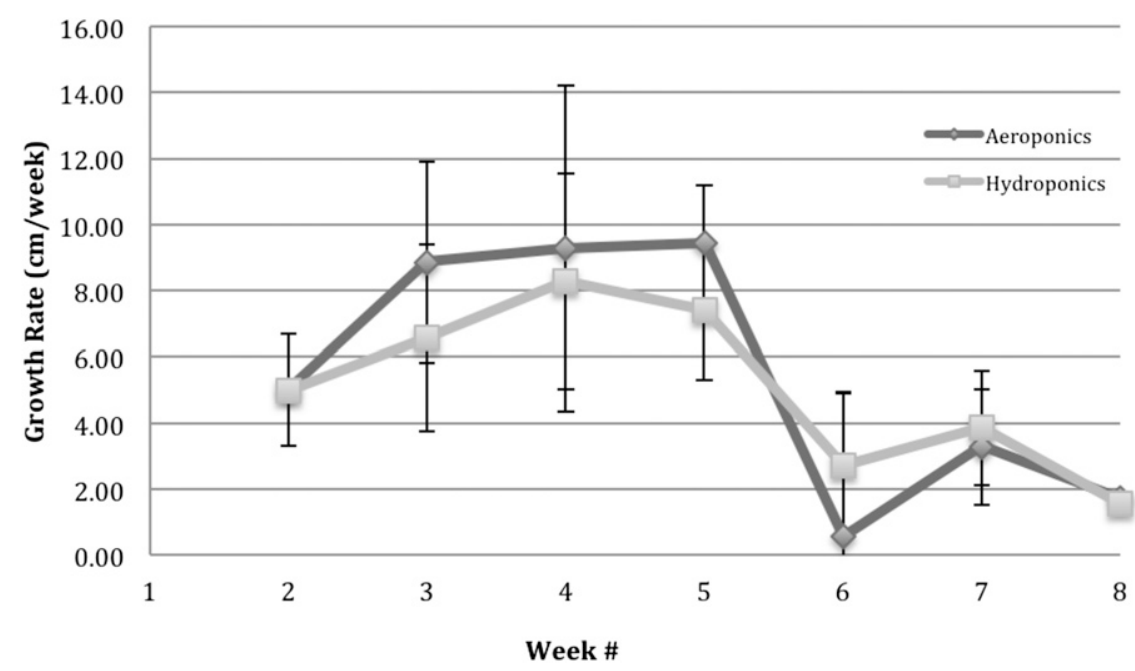

Fig. 2. Plant growth rates in aeroponics and hydroponics. Vertical bars represent $95 \%$ confidence interval. Diamonds and squares represent weekly averages $(n=7)$.

a result of this event, the growth rate of aeroponically grown plants decreased to less than $1 \mathrm{~cm} /$ week and the growth rate of hydroponically grown plants reduced to $\approx 3$ $\mathrm{cm} /$ week. In Figure 1, the effect of the power outage is seen in Week 5 , because plant heights remained almost the same. The trend lines show aeroponic plants with a slightly steeper growth slope, signifying a faster growth rate on average. Additionally, the surface area of the leaves in each system varied largely and yielded only weak trends without statistically significant differences. This can be seen in Figure 3, where the leaves of the aeroponically grown plants were somewhat larger than in the hydroponically grown plants.

As shown in Table 2, aeroponically grown plants produced an average of $49.8 \mathrm{~g}$ DW (sD 20.7). Hydroponically grown plants produced an average of $57.6 \mathrm{~g} \mathrm{DW}$ (SD 16.0). Therefore, there was no significant difference $(P>0.05)$ in aerial biomass production between the two growing methods. The percent DW column (Table 2) indicates what percentage of the wet weight corresponds to actual plant material. Data in this column show that all plant materials were dried to the same extent.

Chemical analysis of the plant materials indicated that the hydroponically grown plants contained significantly higher concentrations of WA $(P<0.05)$. As shown in Table 3, hydroponically and aeroponically grown plants contained an average of 7.8 $\mathrm{mg} \cdot \mathrm{g}^{-1} \mathrm{DW}$ (SD 0.3 ) and $5.9 \mathrm{mg} \cdot \mathrm{g}^{-1} \mathrm{DW}$ (SD $0.6)$ WA, respectively.

\section{Discussion}

Because multiple factors influence plant biomass production, we controlled all feasible environmental conditions (timing of transplanting, temperature, light, nutrient medium, RH, location in the greenhouse, etc.) to reduce variability and to allow more precise comparison of plant growth under the two specified conditions. Additionally, the experiment comprised seven pesudoreplicates in each growing condition to attain accurate results.

In previous studies, Solanum lycopersicum (tomatoes) have been found to produce 


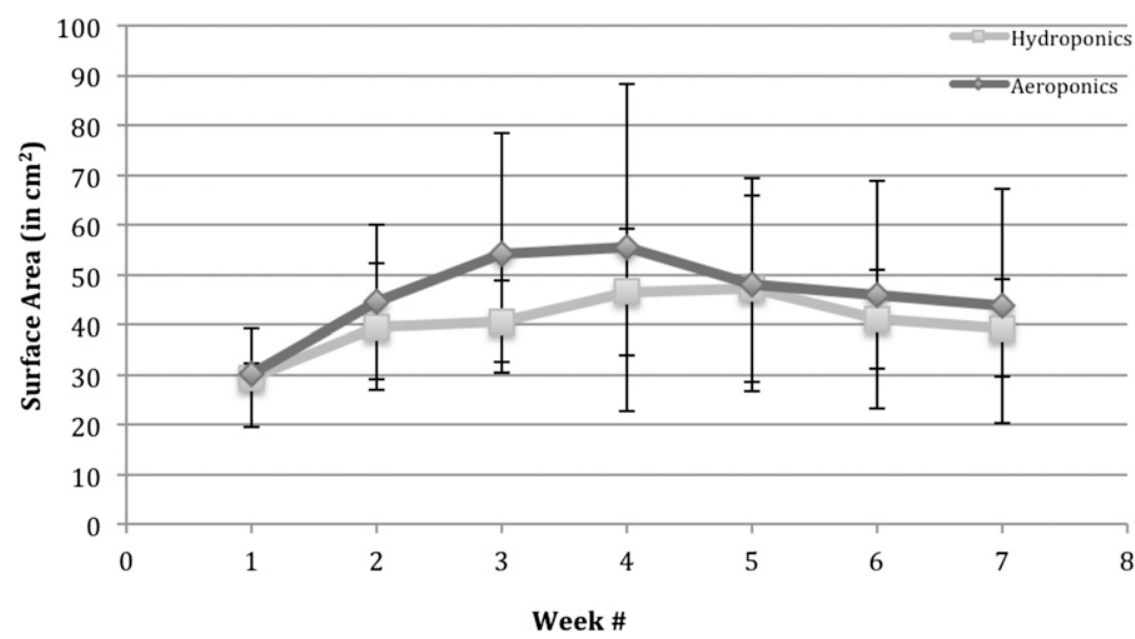

Fig. 3. Leaf surface areas for aeroponics and hydroponics. Vertical bars represent $95 \%$ confidence interval. Diamonds and squares represent weekly averages $(n=6)$.

Table 2. Measured plant biomass for aeroponics and hydroponics. ${ }^{2}$

\begin{tabular}{lccclccc}
\hline & Wet wt $(\mathrm{g})$ & Dry wt $(\mathrm{g})$ & Percent DW & & Wet wt $(\mathrm{g})$ & Dry wt $(\mathrm{g})$ & Percent DW \\
\hline H1 & 291.2 & 51.6 & 17.7 & A1 & 368.6 & 76.1 & 20.6 \\
H2 & 273.7 & 49.3 & 18.0 & A2 & 296.7 & 54.4 & 18.3 \\
H3 & 341.7 & 62.1 & 18.2 & A3 & 260.2 & 44.0 & 16.9 \\
H4 & 545.3 & 91.6 & 16.8 & A4 & 323.7 & 56.6 & 17.5 \\
H5 & 289.8 & 56.0 & 19.3 & A5 & 96.2 & 17.2 & 17.9 \\
H6 & 271.9 & 46.7 & 17.2 & A6 & 421.8 & 69.3 & 16.4 \\
H7 & 263.2 & 45.9 & 17.4 & A7 & 241.8 & 31.3 & 12.9 \\
Total & 2276.8 & 403.2 & & Total & 2009.0 & 348.9 & \\
Mean & 325.3 & 57.6 & 17.8 & Mean & 287.0 & 49.8 & 17.2 \\
SD & 100.4 & 16.0 & 0.8 & SD & 104.4 & 20.7 & 2.3 \\
\hline
\end{tabular}

${ }^{2} \mathrm{H}$ and A signify hydroponics and aeroponics, respectively, and the following numbers correspond the specific plant in that system. The DW column indicates what percentage of the wet weight corresponds to actual plant material.

Table 3. Withaferin A content in dried plant materials for aeroponics and hydroponics. ${ }^{\mathrm{z}}$

\begin{tabular}{lcc}
\hline & $\begin{array}{c}\text { Hydroponics } \\
\left(\mathrm{mg} \cdot \mathrm{g}^{-1} \mathrm{DW}\right)\end{array}$ & $\begin{array}{c}\text { Aeroponics } \\
\left(\mathrm{mg} \cdot \mathrm{g}^{-1} \mathrm{DW}\right)\end{array}$ \\
\hline Sample 1 & 8.1 & 6.7 \\
Sample 2 & 7.7 & 5.5 \\
Sample 3 & 7.6 & 5.6 \\
Mean & 7.8 & 5.9 \\
SD & 0.3 & 0.6 \\
\hline
\end{tabular}

${ }^{2}$ Each sample was independently sourced from the total amount of aerial plant biomass for each system. DW $=$ dry weight.

higher yield in hydroponics and aeroponics than in traditional soil culture (Gysi and Von Allmen, 1997). Additionally, Solanum lycopersicum var. cerasiforme (cherry tomatoes), grown aeroponically, produced higher yields when compared with plants grown hydroponically. The improved yield was attributed to enhanced root aeration (Cho et al., 1996; Soffer and Burger, 1988). In a recent study (Kindscher et al., 2014) the authors discuss the effects of experimental manipulations of nutrients in the soil in which Physalis longifolia were grown. The authors found negligible differences in WA and other withanolides production as a function of these manipulations. However, the authors stress the importance of using genetic isolates of plants to provide for homogeneity so as to reduce secondary metabolite variability. In our study we used seeds from an isolated stock previously grown for several generations at NPC. We suggest, therefore, that genetic variability contributed minimally to the differences in secondary metabolite production in this study such that the differences we found can be more strongly attributed to the growing conditions.

In this study, similar growth patterns and biomass yields of Withania somnifera were observed for both growing conditions. Initially, aeroponically grown plants showed a growth rate that was statistically not different from hydroponically grown plants. As mentioned, a power outage causing a sharp rise in greenhouse temperature combined with irrigation pump failure resulted in reduced plant growth rates in both systems. As expected, this reduction, accompanied by partial wilting, was initially more pronounced in aeroponically grown plants whose roots did not receive any moisture or nutrients during the outage. All plants recovered in both conditions (Figs. 1 to 3 ) and resumed growth within 1 week. The pump failure, which was experienced in our study, may be considered a plant stressor, which therefore may have contributed to an increase in secondary metabolites (WA) production. Because this stress (lack of fertigation) would have been more pronounced in the aeroponics system, one would expect WA synthesis to be higher than in the hydroponic system because in the latter, some nutrient medium continued to bathe the plant roots. Because we found that WA production was larger in hydroponics, it amplifies the significance of our results.

Plants generally display variations in biomass production (likely as a result of genetics and uncontrolled "hidden" environmental factors). To take such variations into account, we removed apparent outlier plants ( $\mathrm{H} 4$ and A5) from the data analysis (not shown), which resulted in identical statistical results as data analysis, which included the outliers. These analyses showed that both soilless growing conditions yielded the same biomass per plant.

In contrast, however, WA content analysis showed statistically significant differences. Plants growing in their natural habitat showed large variations of WA content (Kumar et al., 2007; Mirjalili et al., 2009). For example, naturally occurring plants in Iran were found to contain concentrations of WA ranging from 2.2 to $32.5 \mu \mathrm{g} \cdot \mathrm{g}^{-1} \mathrm{DW}$ (corresponding to $0.0002 \%$ to $0.00325 \%$ ) (Mirjalili et al., 2009), whereas in India, the leaves of naturally occurring plants were reported to contain 0.192 to $1.312 \mathrm{~g} / 100 \mathrm{~g} \mathrm{DW}$ (corresponding to $0.192 \%$ to $1.312 \%$, but mostly less than $1 \%$ ) WA (Kumar et al., 2007). We report here that the aerial parts of our plants grown hydroponically contained an average of $7.8 \mathrm{mg} \cdot \mathrm{g}^{-1} \mathrm{DW}(0.78 \%)$, whereas the aeroponic plants contained an average of $5.9 \mathrm{mg} \cdot \mathrm{g}^{-1}$ DW $(0.59 \%)$. These results show that hydroponically grown plants contained a significantly higher concentration of WA than plants grown aeroponically.

As noted in "Methods," our study does not comprise true replication (repeating the same experiment) but rather relies on analysis from pseudoreplicates. There is an almost equal division of opinion as to the validity of the latter approach with the conclusion that mitigating circumstances often prevent true replication in plant science research. Being aware of this situation, and using the results of our statistical analysis conservatively, we suggest that our findings indicate that WA synthesis using hydroponics is a more efficient system than using aeroponics (Hurlbert, 1984).

Further research is needed to explore the mechanism(s) responsible for the increase in WA production we report here. Still, our findings are likely to have implications for the growing conditions of other medicinal plants where a secondary metabolite is the target compound. Our results indicate that hydroponics (NFT system) is the more effective method for growing Withania somnifera with the goal of reproducibly generating withaferin A. In addition, hydroponics is more suitable for commercial applications because it is less susceptible to problems (e.g., resulting from pump failure). Plants grown hydroponically are also more economically grown and harvested as a result of the ability to customize the layouts of the systems compared with traditional field culture. The soilless conditions also eliminate soilborne pests and prevent contamination by field-growing plants. The results we report in this study suggest that 
other medicinal plants may also synthesize higher concentrations of metabolites in hydroponic conditions, which may be of pharmaceutical interest. Further studies should be undertaken to find the most effective nutrient medium composition, including adjustments to the sources of nutrients as well as changes to $\mathrm{pH}$ and $\mathrm{EC}$, all known to affect biomass production and secondary metabolite synthesis (Hoagland and Arnon, 1950; Nagella and Murthy, 2011).

\section{Literature Cited}

Cho, Y.D., S.G. Kang, Y.D. Kim, K.T. Kim, and G.H. Shin. 1996. Effects of culture systems on growth and yield of cherry tomatoes in hydroponics. RDA J. Agr. Sci. 38:563-567.

Cragg, G.M., P.G. Grothaus, and D.J. Newman. 2009. Impact of natural products on developing new anti-cancer agents. Chem. Rev. 109:30123043.

Dalavayi, S., S.M. Kulkarni, R.L. Itikala, and S. Itikala. 2006. Determination of withaferin-A in two Withania species by RP-HPLC method. Indian J. Pharmaceutical Sci. 68:253.

Gysi, C. and F. Von Allmen. 1997. Balance of water and nutrients in tomatoes grown on soilless systems. Agralforschung 4:28.

Hoagland, D.R. and D.I. Arnon. 1950. The waterculture method for growing plants without soil. Circ. California Agricultural Expt. Sta. 347.2.
Hurlbert, H.S. 1984. Pseudoreplication and the design of ecological field experiments. Ecol. Monogr. 54:187-211.

Jones, J.B., Jr. 2004. Hydroponics: A practical guide for the soilless grower. Vol. 1. CRC Press, Boca Raton, FL.

Kindscher, K., C. Cao, R.J. Gallagher, H. Zhan, Q. Long, L. Service, L.M. Martin, and B.N. Timmermann. 2014. Comparison of bioactive secondary metabolites in experimental and natural populations of wild tomatillos, Physalis longifolia Nutt. Ethnobotany Res. Applications 12:175-182.

Kumar, A., M.K. Kaul, M.K. Bhan, P.K. Khanna, and K.A. Suri. 2007. Morphological and chemical variation in 25 collections of the Indian medicinal plant, Withania somnifera (L.) Dunal (Solanaceae). Genet. Resources Crop Evol. 54:655-660.

Mirjalili, M.H., S.M. Fakhr-Tabatabaei, H. Alizadeh, A. Ghassempour, and F. Mirzajani. 2009. Genetic and withaferin A analysis of Iranian natural populations of Withania somnifera and $\mathrm{W}$. coagulans by RAPD and HPTLC. Natural Prod. Commun. 4:337-346.

Mishra, L., B.B. Singh, and S. Dagenais. 2000. Scientific basis for the therapeutic use of Withania somnifera (ashwagandha): A review. Altern. Med. Rev. 5:334-346.

Muro, J.V.D.G., V. Diaz, J.L. Goni, and C. Lamsfus. 1997. Comparison of hydroponic culture and culture in a peat/sand mixture and the influence of nutrient solution and plant density on seed potato yields. Potato Res. 40:431-438.

Nagella, P. and H.N. Murthy. 2011. Effects of macroelements and nitrogen source on biomass accumulation and withanolide-A production from cell suspension cultures of Withania somnifera (L.) Dunal. Plant Cell Tissue Organ Cult. 104:119-124 [PCTOC].

Soffer, H. and D.W. Burger. 1988. Effects of dissolved oxygen concentrations in aerohydroponics on the formation and growth of adventitious roots. J. Amer. Soc. Hort. Sci. 113:218-221

Souret, F.F. and P.J. Weathers. 2000. The growth of saffron (Crocus sativus L.) in aeroponics and hydroponics. J. Herbs Spices Med. Plants 7:25-35.

South, B.D. and G.L. Somers. 2009. PseudoreplicationPart 1. Thesis, Auburn Univ., Auburn, AL.

Wilson, J.B. 2007. Priorities in statistics, the sensitive feet of elephants, and don't transform data. Folia Geobot. 42:161-167.

Xu, Y., M.T. Marron, E. Seddon, S.P. McLaughlin, D.T. Ray, L. Whitesell, and A.A.L. Gunatilaka. 2009. 2, 3-Dihydrowithaferin A-3 $\beta$-O-sulfate, a new potential prodrug of withaferin A from aeroponically grown Withania somnifera. Bioorg. Med. Chem. 17:2210-2214.

Zobel, R.W., P. Del Tredici, and J.G. Torrey. 1976. Method for growing plants aeroponically. Plant Physiol. 57:344-346. 